\title{
Analysis of the deactivation of ZSM-5 catalyst during MTO reaction in a periodic operating fixed bed reactor
}

\author{
Héctor Vicente ${ }^{*}$, Tomás Cordero-Lanzac ${ }^{a}$, Ana G. Gayubo ${ }^{a}$, Pedro Castaño ${ }^{b}$ \\ aDepartment of Chemical Engineering, University of the Basque Country (UPV/EHU), P.O. Box 644, E48080, Bilbao, Spain \\ ${ }^{b}$ Multiscale Reaction Engineering, KAUST Catalysis Center (KCC), King Abdullah University of Science and Technology (KAUST), \\ Thuwal, 23955-6900, Saudi Arabia \\ *hector.vicente@ehu.eus
}

\begin{abstract}
A set of methanol to olefins (MTO) reactions has been performed in a fixed bed periodic operating reactor with a low acidic ZSM-5 zeolite catalyst. The experimental set-up of the periodic reactor allows the operation in fast heating cooling cycles, therefore obtaining coke formed by distinct pathways. The conversion of oxygenates and yields of products have been analyzed for both conventional fixed bed and periodic operating reactor and the deactivated catalyst has been characterized by different methods and then compared to those obtained for the fresh catalyst. Our results show that periodic operation is a suitable option for extending the lifetime of the catalyst compared to the conventional steady operating MTO reaction. The stability increase is proportional to the length of the oscillation period. The analysis of the coke samples obtained with periodic operation combined with the information obtained by improved techniques such as catalyzed combustion of coke open a new approach to understanding the catalyst deactivation in MTO reaction.
\end{abstract}

Keywords: MTO, Periodic operation, ZSM-5, catalyst deactivaction, coke analysis.

\section{Introduction}

Methanol to olefins (MTO) reaction is an industrially well developed and deeply studied process that enables an alternative route for obtaining petrochemical intermediates (Nesterenko et al., 2016). Still, further investigation in this reaction is appealing as MTO offers a sustainable route for olefin production from biomass via syngas.

Current research mainly focuses in the study of deactivation by the formation of large depositions of coke, that block the active sites located within the pores of the zeolite triggering the deactivation of the catalyst. Several methods have been proposed in order to diminish the effect of this deactivation (Valecillos et al., 2019), but a deeper comprehension of the formation of coke is still needed.

Periodic operation presents itself as a suitable option for the control of the catalyst deactivation. It is a developing technique which involves the forced periodic modulation of an operation parameter of the system like temperature, pressure or feed flowrates, while the reaction is taking place. The variation of this operation parameter or input variable causes a modulated response of one or more of the output variables (Silveston and Hudgins, 2013). In a chemical system this output variables may include direct results such as feed conversion, product yield or selectivity, or intrinsic variations like changes in the catalyst stability or deactivation mechanisms.

In this work, the reaction indexes (conversion of oxygenates (methanol and dimethyl ether) and yields of products) and variations of coke structure formed in MTO reaction during temperature modulated experiments have been analyzed. The results have then been compared to those obtained in the steady operation.

\section{Experimental}

The experimental set-up consists of a fixed-bed reactor covered by a jacket with a cold air inlet. This air is directed to the external part of the catalyst bed in order to provide a fast cooling system to the reaction environment. The products are analyzed on-line with a Micro-GC (Varian CP-4900).

A ZSM-5 zeolite-based catalyst (Zeolyst International CZ-280) with low acidity (Si/Al ratio of 140) was used. The zeolite was agglomerated by physical mixture with pseudo-boehmite to provide mesoporosity and extra mechanical stability. The mix was then calcined to $575^{\circ} \mathrm{C}$ to stabilize it to the reaction conditions.

The characterization of both fresh and deactivated catalyst consisted of $\mathrm{N}_{2}$ adsorption-desorption, Temperature Programmed Desorption (TPD) of $\mathrm{NH}_{3}$ and thermogravimetric analysis. The latter has been performed by Temperature Programmed Oxidation (TPO) of the accumulated coke in the deactivated catalyst, both with and without catalyzing the combustion of the coke by physically mixing a $1 \mathrm{wt} \%$ of $\mathrm{Cr}$ with the deactivated catalyst sample (Wang et al., 2019).

\section{Results}

The comparison of oxygenates conversion obtained for the reactions (Figure 1) show that periodic operation improves catalyst stability. Increasing the length of the modulation period reduces the loss of activity of the catalyst, maintaining the conversion level higher at longer TOS. A 5 minute period temperature modulation between 425 and $475{ }^{\circ} \mathrm{C}$ has nearly no enhancement compared to the steady operated reaction, whereas a 10 minute period modulation keeps the activity level of a $425^{\circ} \mathrm{C}$ steady operation reaction after the 16 hours of reaction.

Furthermore, a $32 \mathrm{~h}$ period oscillation (decreasing temperature from $450{ }^{\circ} \mathrm{C}$ to $425{ }^{\circ} \mathrm{C}$ and back to $450{ }^{\circ} \mathrm{C}$ ) reaches a conversion of $80 \%$ compared to the $45 \%$ of the $425^{\circ} \mathrm{C}$ reaction after the $16 \mathrm{~h}$ of reaction, whereas the opposite temperature modulation shows nearly no difference to the $450^{\circ} \mathrm{C}$ steady operation reaction (Figure $1 \mathrm{~b}$ ). 

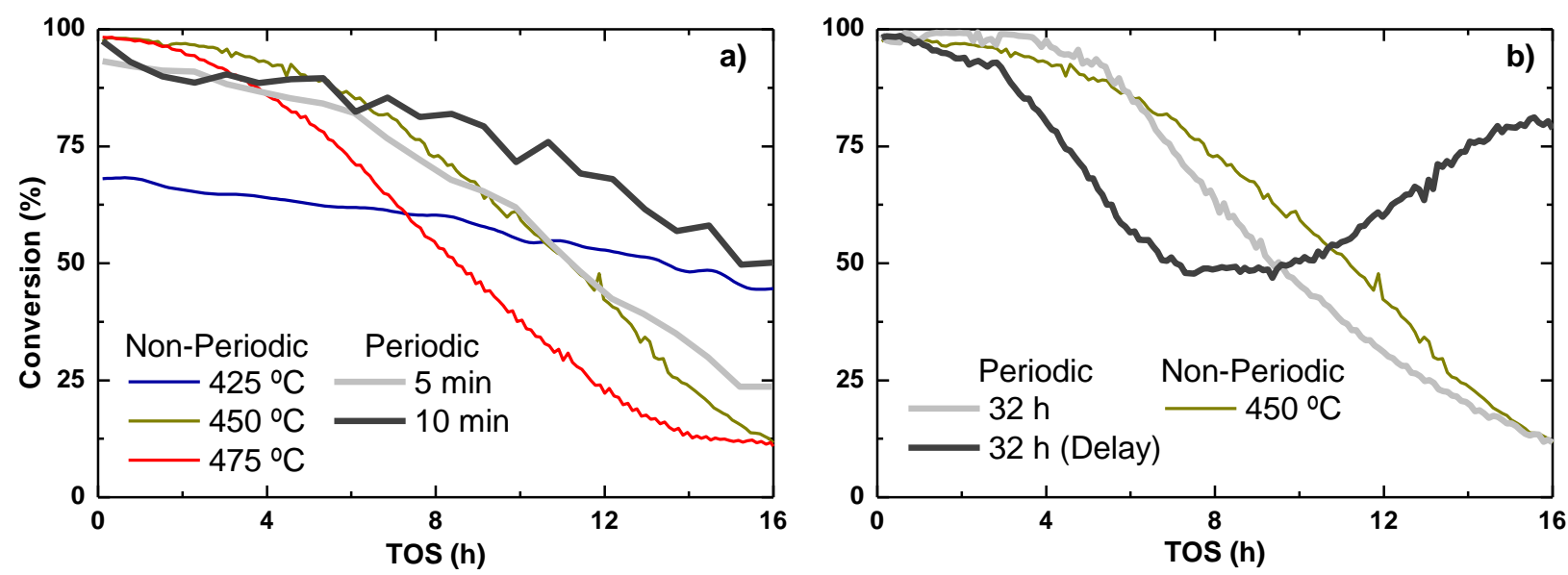

Figure 1. Oxygenates conversion for non-periodic reactions and periodic reactions of amplitude $25^{\circ} \mathrm{C}$ and initial temperature of $450^{\circ} \mathrm{C}$ a) Periods of 5 and 10 minutes; b) Periods of $32 \mathrm{~h}$ and $32 \mathrm{~h}$ with a $16 \mathrm{~h}$ delay.

This behaviour is consistent with the TPO results, which show lower coke formation in the periodic operation experiments. These coke contents vary from 2.8 to $8.2 \mathrm{wt} \%$ in the steady operation experiments (increasing with temperature) and between 4.8-3.6 wt \% in the periodic operation experiments, decreasing with period length.

The catalytic combustion method is capable of splitting the TPO profile in two distinct peaks. The first one corresponds to the external coke, which appears at lower temperatures, as it is catalyzed by effect of the Cr whereas the second peak is attributed to the internal coke which does not interact with the $\mathrm{Cr}$.
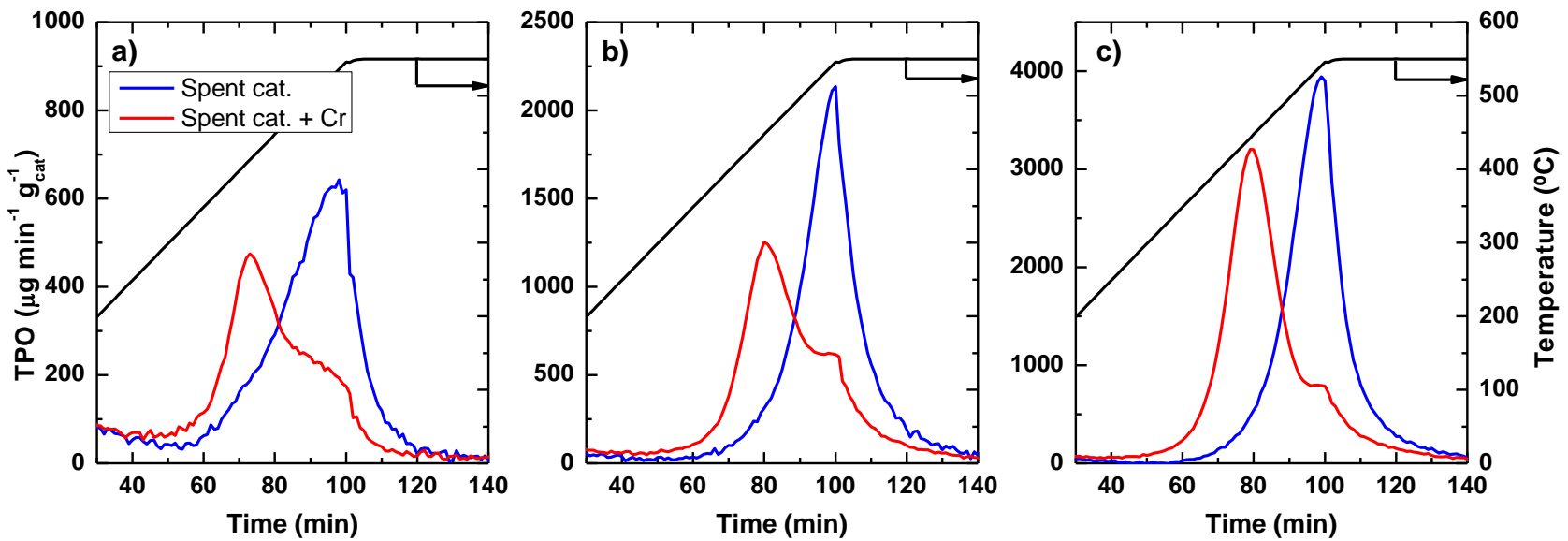

Figure 2. TG-TPO profiles of the deactivated catalyst. $\tau$ : $1 \mathrm{~g}_{\text {cat }} \mathrm{h} \mathrm{mol}-1$; a) T: $425^{\circ} \mathrm{C}$; b) T: $450{ }^{\circ} \mathrm{C}$; c) T: $475^{\circ} \mathrm{C}$

The area of each peak can be extracted by deconvolution therefore establishing a relationship between internal and external coke. This ratio decreases with temperature as the interior of the pores gets saturated with coke while in the exterior the carbon structure keeps on getting larger as the reaction continues.

\section{Conclusions}

Periodic operation has proven to be a useful methodology for the improvement of the MTO process, especially concerning the catalyst stability. It also provides a set of deactivated catalyst, with the coke formed through different routes.

Catalyzed combustion by $\mathrm{Cr}$ addition has been useful for extracting additional information from the coke in terms of internal and external coke differentiation.

\section{Acknowledgements}

Authors fully acknowledge the financial support received from the Ministry of Economy and Competitiveness of the Spanish Government (MINECO), through project CTQ2016-79646-P, The Basque Government (IT748-13) and ERDF funds. Héctor Vicente is grateful for the Ph. D. grant from the Basque Government.

\section{References}

Nesterenko, N., Aguilhon, J., Bodart, Ph., Minoux, D., Dath, J.-P., 2016. "Methanol to Olefins: an insight into reaction pathways and products formation." Zeolites and zeolite-like materials, 189-263. https://doi.org/10.1016/B978-0-444-63506-8.00006-9.

Silveston, P. L., Hudgins, R. R., "Periodic operation of Reactors", 2013, Oxford, Elsevier/BH. https://doi.org/10.1016/C2010-0-673020 .

Valecillos, J., Epelde, E., Albo, J., Aguayo, A. T., Bilbao, J., Castaño, P., 2019. "Slowing down the deactivation of H-ZSM-5 zeolite catalyst in the methanol-to-olefin (MTO) reaction by P or Zn modifications." Cat. Tod. In press. https://doi.org/10.1016/j.cattod.2019.07.059

Wang, T., Chen, M., Liu, X., Zhang, Z.-G., Xu, Y., 2019. "Distinguishing external and internal coke depositions on micron-sized HZSM-5 via catalyst-assisted temperature programmed oxidation." New J. Chem., 43, 13938. https://doi.org/10.1039/c9nj02899d. 